Archived version from NCDOCKS Institutional Repository http://libres.uncg.edu/ir/asu/

\title{
Appalachľan
}

B O O N E, NORT H CAROL I N A

\section{Looking At Journals From Both Sides}

\author{
By: Norman Clark (With Allan Scherlen as editor)
}

\begin{abstract}
The author, a professor in the field of communication, describes his contrasting experiences with publishing an open access society journal and advising a regional association in regards to turning over publication of its journal to a major commercial publishing firm. Using his experience of producing an open access journal as a foundation, he argues for the intrinsic importance of establishing credibility and exercising personal care in the production and maintenance of a journal. The author argues that current efforts by some societies to increase access to their journals through outsourcing to commercial publishers may be counterproductive to the fundamental goal of disseminating knowledge.
\end{abstract}

Clark, N \& Scherlen, A (2005) "Looking At Journals From Both Sides" Serials Review, Volume 31, Issue 4, pp. 284-290 Version Of Record Available At Elsevier 


\section{ARTICLE}

\section{Editor's Introduction}

A column such as the "Balance Point" provides an ideal forum for personal perspectives on important serial issues not easily dealt with in formal articles. For this issue of "Balance Point" our contributor shares his joys and frustrations experienced while being immersed in two very different but related sides of society journal publishing: working with a small group to produce an open access journal and participating in an association decision on whether to hand over the society's journal to a commercial publisher. Dr. Clark takes us on a journey of both heart and mind. He confides in us about his thoughts and feelings on raising an open access journal from infancy to maturity. We are invited to share in the feeling of success as the journal gains credibility and in loss as it declines. We are then offered a seat in a committee meeting to watch as he makes a desperate attempt to alter the fate of another society journal destined for the corporate block. Such personal stories of inner struggle in coming to terms with the future of scholarship complements the analytical assessments found in our journal literature. 


\section{Introduction}

I've looked at clouds from both sides now -- From up and down, and still somehow -- It's cloud illusions I recall -- I really don't know clouds at all

1

When I first began to climb the ivory tower, I was enthralled by the beauty of higher education. Studying the human condition from the perspective gained by reaching the level of the clouds, and then sharing that knowledge freely with others, was one of the more admirable callings I could imagine. As most in academia would agree, teaching is an act of service and, as such, enriches both the people being served as well as the person doing the service. And so it was with high hopes in the ideal of a life of service to knowledge that I entered.

At some point, however, the clouds became overcast. Over the past five years, I have been heavily involved in several different aspects of the production of knowledge, specifically journal publishing. I had the pleasure of serving as the associate editor of an online journal for three years, followed by the pain of serving on the publications committee for a regional association as it struggled with the decision to turn over its journal to a large publishing house. In the paragraphs to follow, I will recount both sides of my experience in journal publication. It is my hope that others may learn from my climb and perhaps help revive the illusive ideal of freely shared knowledge.

\section{Side A}

Moons and Junes and Ferris wheels-- The dizzy dancing way that you feel -- As every fairy tale comes real -- I've looked at love that way

\section{2}

The American Communication Association (ACA)3 was founded in 1993 for a variety of reasons, including a belief that the existing national association (at that time called the Speech Communication Association, and since then renamed the National Communication Association4) had several shortcomings. The ACA had several shortcomings, such as a failure to utilize new communication technologies. One of the first acts of the ACA was to start a new journal, the American Communication Journal (ACJ), 5 which was dedicated to two fundamental principles: (1) it would be an onlineonly journal, and (2) it would always be free and open access. The journal launched in 1997, with an issue auspiciously titled "The Dawning of Online Interactive Scholarship.” Several respected names in the field speculated about the potential for online scholarship and a future where research would no longer be statically bound to fixed printed pages.

As is the case with any new journal, one of the ACJ's initial struggles was to attract quality submissions. The inaugural editors, James Kuypers and Tyrone Adams, worked the networks - e-mail, telephones, and face-to-face interactions at conferences - to encourage both established researchers as well as rising stars to submit articles. Also relying on special issues with guest editors, Kuypers and Adams did an admirable job of 
filling the first three years with articles ranging across the entire communication discipline. When they turned the journal over in 2000 to Stephanie Coopman and myself, it had begun to attract scholars interested in publishing articles without page limit concerns and with the potential to include multimedia content.

One of the first things that Stephanie Coopman and I agreed on was a division of labor: as editor, Dr. Coopman would handle the traditional tasks of gathering articles and shepherding them through the peer-review process, while as the associate editor I would deal with the "untraditional" tasks of designing and coding the Web site. When I began to redesign the Web site, my primary concern was to increase the perceived credibility of the journal.6 Within the communication discipline, and in particular the subfield of persuasion, credibility is seen as an audience construct. In other words, the audience assigns credibility to a speaker, and thus to gain credibility the communicator must first consider his or her audience. In addition, credibility has both primary and secondary dimensions. The primary dimension includes trust and expertise, while the secondary dimension includes several concepts, one of which is applicable to design: charisma.7 Thus, I saw myself facing a fourfold task: evaluating the audience, establishing expertise, earning trust, and exuding charisma. But I was excited to take on this labor of love, seeing in it a chance to broaden access to communication scholarship.

The obvious audience for the ACJ, both in terms of readers as well as authors, was academics on the "cutting edge" of technology, authors who were comfortable with using Web browsers, word processors, and (in some cases) multimedia software. However, Dr. Coopman and I agreed that if the journal was to grow, it would need to appeal to a broader audience. In addition, because most of the contributors were faculty members still seeking tenure, the journal needed to appear credible and accessible to the already tenured faculty who served on promotion and tenure boards. Because most tenured faculty in 2000 had published primarily (or even exclusively) in print journals, I reasoned that the redesigned journal would need to emulate some features of print. If audiences' experience of the journal—reading the pages, finding the articles and references, etc.was not similar enough to their experiences with print journals, those less familiar with online journals (and thus less predisposed to grant credence to new forms) might question the journal's credibility. Thus, the journal's design had to both fit the more traditional audience's expectations for academic journals as well as the cutting edge audience's expectations for online materials. The most obvious change to come from this audience analysis was to make each issue's index page look more like the index page of a print journal and reducing clutter (compare Fig. 1 with Fig. 2). To meet the expectations of the tech-savvy audience, we added features such as a search engine and pop-up reference lists. 


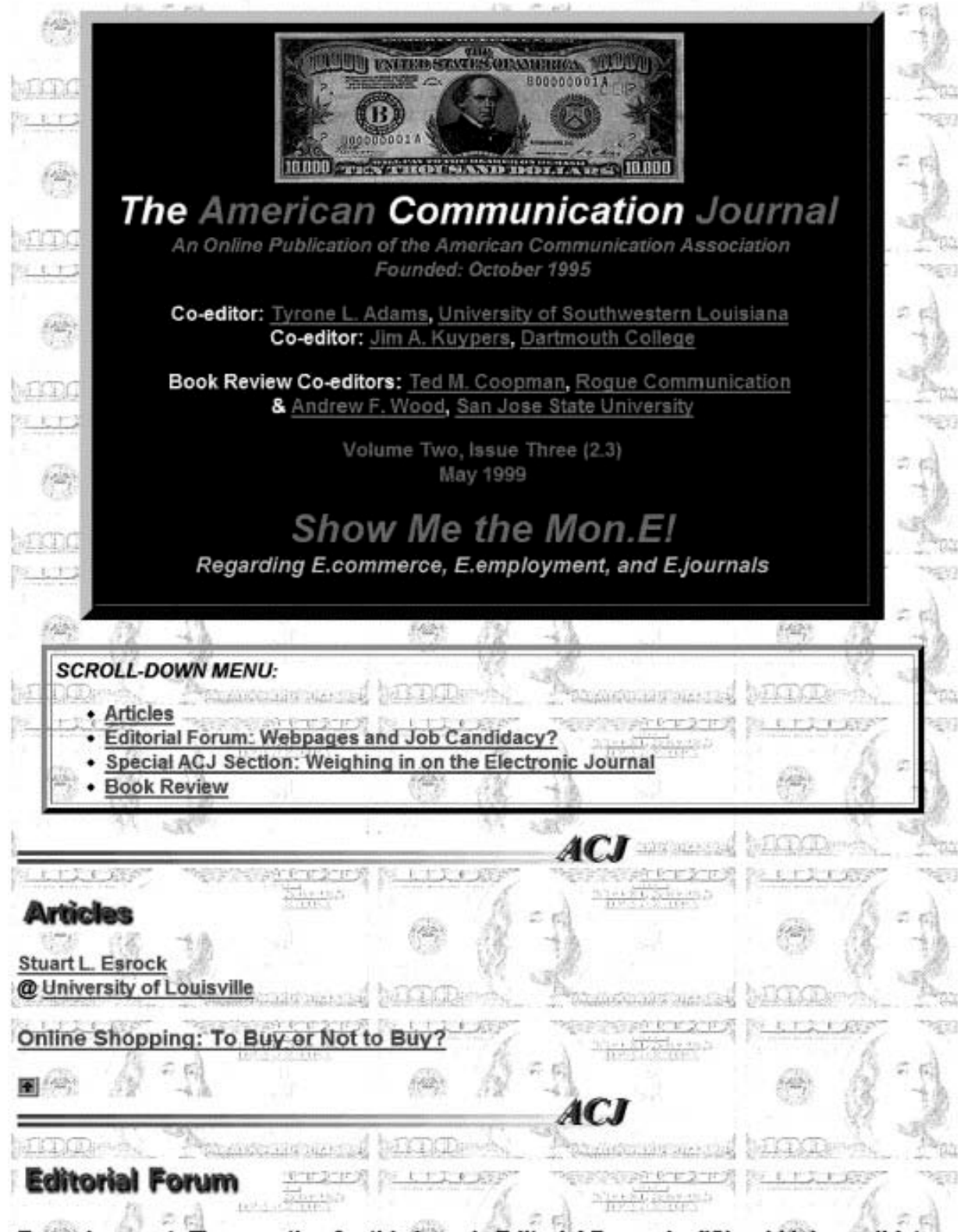

E.employment: The question for this issue's Editorial Forum is: "Should job candidates in communication have a web page?" As usual, we simply ask the question, and provide a free-forum for response.

James Arnt Aune

@ Texas A \& M University

The Webpage and the Job Candidate: Another Fad?

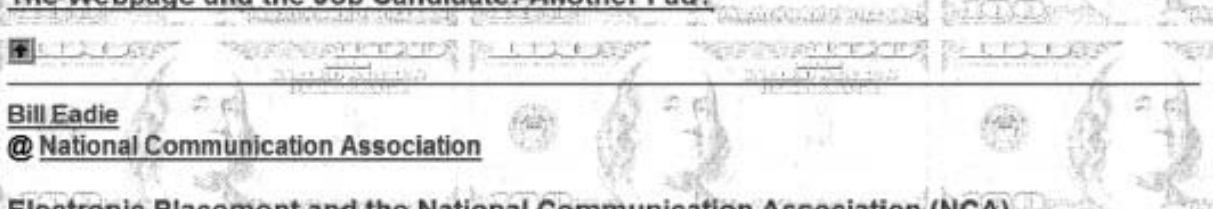

Electronic Placement and the National Communication Association. (NCA)

Figure 1. American Communication Journal Issue Page before Redesign. 


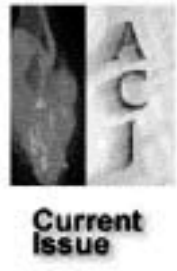

Archives

Editorial

info

Search

Interact

\title{
American Communication lournal
}

Stophanie Coopman \& Norman Cark, Editors

Pybdishod by the funerican Cammerimicarlon Association

\section{Religion, Politics, and Rhetoric -- Discussed Online}

Volume 4, lssue 1, Fall 2000 I Anticles I Special Section I Book Reriews

Note from the Editors

\section{Articles...}

Altar Rhetoric and Online Performance: Scientology, Ethos, and the World Wide Web Todd S. Frobish, Iona College

My Govemor Can Whup Your Govemor's A. Jesse Ventura Wrestles the Local Press to a No

Decision - A Rhetorical Analysis of the

Playboy Scandal

Carl Isaacson, St. Otaf College

\author{
Special Section... \\ Criticism, Politics, and Objectivity \\ Guest Editor. Jim A. Kuypers \\ On Objectivity and Politics in Criticism \\ Edwin Black, Professor Emeritus, University of \\ Wisconsin \\ Criticism of Political Rhetoric and Disciplinary \\ Integrity \\ Craig R. Smith, California State University, \\ Long Beach \\ Back to Tor
}

Must We All Be Political Activists?

Jim A. Kuypers, Dartmouth College

Critical Claims, Critical Functions: Autocthourraply and Postacholarship

Jill Taft-Kaufman, Central Michigan University

\section{Book Reviews...}

John McGrathe \& Steve Schwarze, Co-Editars

Cop Talk Essential Communication Skills for Community Policing

Authors: Virginia Kidd and Rick Braziel

Reviewer. Kevin Brown, Montana State

University-Northem

Seeing Spots: A Functional Analysis of Presidential Television Advertisements. 1952-1996

Author: William L. Benoit

Reviewer. Fredel M. Wiant, University of Utah

Back to Top

Home $\mid$ Current Issue $\mid$ Archives | Editorial Information | Search | Interact
I Know Just What You Mean: The Power of Friendship in Woman's Lives

Authors. Ellen Goodman \& Patricia O'Brien Reviewer. Joy Hart, University of Louisville

Tume in. Log on Soaps, Fandorn, and Online Comminity

Author: Nancy K. Baym

Reviewer: Beth Fratkin, University of Utah

Figure 2. American Communication Journal Issue Page after Redesign. 
The expertise of any journal is established primarily through the quality of the articles, with a not insubstantial boost coming from authors' existing reputation. To emphasize this in the redesign of the site, I worked to privilege the articles in their placement on the site. For example, note in Figure 1 that a significant portion of the older index page was taken up by other content, pushing the articles to the bottom, and numerous links led one away from the journal contents to such ancillary things as the authors' institutions. Figure 2 shows how the redesigned index pages for each issue placed the articles closer to the top, hid editors' notes in pop-up boxes, and (with a few exceptions) included only links to the journal contents.

An online journal's reputation also heavily depends on the functionality of the site. The smoothness of interaction on the site can enhance or detract from a readers acceptance of an online journal. Thus, quality was enhanced in the ACJ by ensuring that the site was fully functional and well organized. Regular checking and maintenance of links, graphics, and other elements helped communicate a high level of professionalism.

Trust, the other primary dimension of credibility, takes time to earn. But in the absence of years to develop a relationship with its readers, an online journal can take certain steps to earn the trust of its audience. Because trust increases as uncertainty decreases, it was important for us to demonstrate that the journal was committed to a long-term relationship with its authors and readers. Purchasing an identifiable and unique domain name (acjournal.org) was one way to show that the journal planned to be around for a while. Registering with the Library of Congress and obtaining an ISSN number were further signs of the legitimacy of the journal. Prominently posting editorial practices, contact information for all of the editors involved, evidence of institutional support, and opportunities for reader interaction furthered the image of the journal as a trustworthy source of information and outlet for publication.

In addition to the primary dimensions of establishing trust and expertise, credibility of a new journal also depends on several secondary dimensions that may be somewhat less importance as well as nebulous. One of the most difficult to pin down is dynamism, or charisma. We all know a charismatic speaker when we see one. The charismatic person generally has a strong personality and the ability to grab the audiences' attention and hold it. In the redesign of the ACJ site, I tried to strengthen the personality of the journal by developing and maintaining a consistent, attractive look across the entire site, and from issue to issue. A comparison of Volumes 1-3 with Volumes 4-6 reveals how the identity of the journal was made more coherent. For example, a subtle feature of the site's personality was in the redesign of the links to external sites in Volumes 4-6. Instead of replacing the journal's page in the Web browser, a link opens a smaller browser window free of any navigation buttons or other toolbars that might distract a reader. This was done to encourage readers to regard external sites as illustrations within the articles and to keep their focus on the journal article itself-in other words, to grab their attention and hold it.

The redesign of the site, along with the tireless editorial work of Dr. Coopman in soliciting high-quality submissions, elevated the American Communication Journal to the 
dizzying heights at the top of the Ferris wheel, so to speak, by the summer of 2003. Authors were beginning to explore the new possibilities of the online medium, including multimedia installations where visitors browsed through instead of reading an article in the traditional linear sense. 8 The ACJ genuinely felt like a fairy tale come true: an open access, completely free of charge, exclusively online academic journal had matured into a viable outlet for scholarship with a high level of readership. During our peak year of 2003, we were averaging well over 100,000 visits per month from countries all over the world.9 At that time, the ACJ would turn up in the top three results of a Google search for the word "communication." As a result, the journal was getting a large number of visits from students whose research efforts increasingly go no further than such a search.10 This was encouraging, because any scholar would prefer to see students reading and citing peer-reviewed research instead of accessing "Billy Bob's Hunting and Conflict Resolution” Web site.11 Particularly enjoyable for me were the e-mails I received from librarians and readers around the world, asking if the journal really was free or thanking us for making it so. I had mixed emotions stepping down after a threeyear term as associate editor. On the one hand, I was happy to be free of the responsibility of coding the site and to be ending on such a high note, but, on the other hand, the issue of improving access to scholarly publications had become so important to me I did not want to let go.

\section{Side B}

But now it's just another show -- And you leave 'em laughing when you go -- And if you care, don't let them know -- Don't give yourself away

\section{2}

Now that I have described my experience in helping to inexpensively produce an open access society journal, I wish to juxtapose that against another challenge that confronted me at the time: trying to convince a regional society not to outsource their journal to a corporate publisher. During the spring of 2002, while I was on the upward swing of the Ferris wheel of publishing ACJ online, I was asked to serve on the Publications Committee of the Southern States Communication Association (SSCA). I agreed to serve on this committee for a number of reasons, but especially because it afforded me an opportunity to advocate for increased access to scholarship, in this case, by putting the Southern Communication Journal (SCJ) online. At that time, full text of the association's journal was not available online. I knew the association was considering online access; I wanted to be a part of the decision making process and do my best to ensure that such access was as open as possible.

Shortly after I joined this committee, the National Communication Association (NCA) signed a contract with Taylor and Francis to publish and distribute their journals, including online access to full text for members and subscribers. The NCA also signed with EBSCO to include all of the NCA journals in EBSCO's new Communication and Mass Media Complete (CMMC) index. With the national association taking such a step, it was only a matter of time before the regional associations began to consider such a 
move. I volunteered for and was put on an ad hoc committee to make a recommendation to the association about whether it ought also to turn over the business side of the SCJ to Taylor and Francis and to include its contents in EBSCO's CMMC index. I took the charge quite seriously.

Over the next two years, I researched this issue in great depth. I spoke with librarians both at my home institution (Appalachian State University) as well as those at other institutions in the region. I read through the multitude of arguments presented on the SPARC Web site,13 explored the wide range of possible models to emulate on the Directory of Open Access Journals, 14 spoke with representatives from EBSCO and other content aggregators, attended a meeting for the fledgling Academic Serials in Communication Unified System project,15 and poured over the financial records for the SCJ. Based on this research and additional digging and conversations, I came to the conclusion (shared, no doubt, by many readers of this journal) that if SSCA's goal was to ensure and increase access to their members' scholarship, they should not sign a contract with Taylor and Francis and should sign only non-exclusive contracts with content aggregators such as EBSCO. In fact, if the goal of open access was truly the association's primary goal, signing a contract with a large multinational publishing corporation seemed a step backward. I knew from my own experience that with a shoestring budget and a few dedicated volunteers, an online journal could provide free access to scholarship to a world wide audience. I was convinced that with the coming of the Internet, associations were no longer dependent upon publishers to provide access to their members' researchand publishers unfortunately realize this far better than the associations do.

I walked into the executive committee meeting at the SSCA's convention in the spring of 2005 and gave myself away. Full of the passion of my idealism, I argued that as servants of the public it was our duty to ensure open access to our scholarship (much of which, after all, was supported by tax dollars). I warned that signing a contract with Taylor and Francis, a corporation with a duty to its stockholders to make money, would only end in restricted access and higher costs to readers (in this case, Taylor and Francis planned to triple the library subscription rate for SCJ). I tried to persuade my colleagues to care, but I failed. I did not quite "leave 'em laughing," but it was clear that their minds were made up.

It is perhaps not altogether accurate to say that I failed to get those involved to care. Some of the members of the executive committee did share my concerns. And some of the members at the general business meeting, where the motions to sign contracts with Taylor and Francis and EBSCO passed, also expressed agreement with my arguments for retaining control and providing open access (encouraging signs, since I was only allotted three minutes to make rebuttals to Taylor and Francis' unlimited time to speak and answer questions). But I ultimately discovered that most of my colleagues that day did not share my vision of making the results of our research as openly available as possible. Many of the arguments that I borrowed from SPARC and other open access-promoting Web sites failed to resonate. Relatively few apparently cared that a contract with a commercial publisher might restrict access to their scholarship. And almost no one felt any concern over tripling the library subscription rate ("it's not my money"). I obviously 
did not have time during my brief presentation to go into issues about copyright retention or the loss of control that goes with surrendering ownership. What they cared about the most was that (a) Taylor and Francis would assume most of the "headaches" (in other words, business aspects) that go with publishing a journal, (b) that they would be guaranteed a certain minimum royalty amount every year, and (c) that the journal would be marketed worldwide with the communication journals of the national and other regional associations (all of whom had signed contracts with Taylor and Francis by this point) with the backing of Taylor and Francis' considerable resources. I admit that these are not insignificant considerations (although I personally have never subscribed to an academic journal due to marketing efforts), but I had believed, perhaps naively, that the goal of maximizing access to members' scholarship ought to be the overriding concern. Walking away from that meeting, I definitely felt I had ridden full circle down to the other side of the Ferris wheel and was stepping off at the bottom.

\section{Reclaiming Life's Illusions}

I've looked at life from both sides now -- From win and lose and still somehow -- It's life's illusions I recall -- I really don't know life at all

16

In recent months, more people in communication associations have discovered the dangers of attempting to ride the corporate tiger. For example, an outcry was raised in the spring of 2005 on the NCA's e-mail listserv, CRT-NET, over Taylor and Francis charging all authors other than the first author for reprints of their own works. Earlier in the year, numerous faculty members at institutions around the country discovered they no longer had access to EBSCO's CMMC. It had been included for free as part of their Academic Search Elite database during the first year (2004), but then became a separate database (with an additional fee) that some libraries did not pick up. However, interestingly, the journal editors and Associations' administrative staffs continue to be pleased with their marriage to Taylor and Francis, at least so far.

Though I painted a rosy picture of the American Communication Journal, all is not a win on that side either. The editor who took over the reins in 2003 made the following bold statement in a call for papers on the Web site:

I see my role as editor of ACJ as steward of limited and unique scholarly space: the digital environment. There are literally hundreds of paper based journals that aid in the dissemination of communication scholarship. There are a mere handful that undertake that same vital task in digital space. It is that incredibly tilted playing field that has persuaded me to simply not accept, even for review, manuscripts that can comfortably appear on the printed page. I realize the importance of publication in our academic world, and have already been told that my position has threatened careers and is inexcusably arrogant. Naturally, I see it a bit differently. 
At the time I served as associate editor of the online journal, I agreed in principle with giving priority to content that required such a medium. However, experience has taught me that online journals must be flexible enough to include traditional forms. And practically speaking, there are just not enough scholars producing multimedia and other works designed explicitly to make use of online technology to warrant such restrictions. In hindsight, it would have been more effective for the new ACJ editors to work toward increasing the percentage of Web-enhanced articles (as had been our practice) instead of trying to make a complete break all at once. Consequently, the ACJ has fallen on hard times, dropping from four issues per year to one in two years. Only one issue was released from the summer of 2003 until now (the summer of 2005) — a disappointment, to say the least. Clearly, an online journal that wants to publish only Web-tailored works needs to be extremely active in its solicitation of appropriate submissions. I do not want to assume a decline of caring here as well, but part of me cannot help but reach that conclusion. The most troubling afterthought on all this is that credibility of a journal we worked so hard to build is in danger of quickly being lost. The effort to rebuild that trust and, in turn, the journal's reputation will take much time. I hope the incoming editors care enough to put forth the effort required.

So how do we get our colleagues in academic associations to care about issues in scholarly communication? If decision makers within associations are not moved by the arguments for open access but instead are more interested in reducing their publishing workload and increasing the monetary rewards of a journal product, how can those of us who wish to reverse the trend toward the commodification of academic research persuade their associations to consider other options? I wish I had a simple answer to this question, but I am afraid the only answer is time. Over time, we will need to gather data about the impact on associations' earnings and on what trade-offs associations must make when they turn over the business side of their journal to a for-profit corporation. It is difficult to know, of course, whether a commercialized society journal has lost readership, whether access is actually being expanded or reduced by going commercial. But because this question failed to generate concern among my association colleagues before the decision to outsource our journal was made, I have doubts about its efficacy to do so after the deal becomes ever more rooted over time.

Win or lose, I am still dedicated to working for open access to scholarly work. Perhaps the only way we can create change is by refusing to accept the status quo of the publishing world and holding on to our dreams, to what others may call illusions. Some illusions, after all, are so important that they are worth struggling to make real. I plan to continue to fight for the illusions of free access to scholarly knowledge that I recall rather than accept the unreality of commodification that I really do not want to know. I remind myself that the contracts must be renewed someday. 


\section{References}

1. Joni Mitchell, "Both Sides Now” (CCrazy Crow Music/Sony/ATV Tunes LLC (ASCAP), 2000), http://www.jonimitchell.com/BSNLyrics/BothSidesNow.html (accessed July 16, 2005).

2. Ibid.

3. More information about the American Communication Association is available on their Web site, http://www.americancomm.org (accessed July 16, 2005).

4. More information about the National Communication Association is available on their Web site, http://www.natcom.org (accessed July 16, 2005).

5. The American Communication Journal can be found at http://acjournal.org (accessed July 16, 2005).

6. To see how the journal was redesigned, compare "Transitions," American Communication Journal 3, no. 3 (2000), http://acjournal.org/holdings/vol6/iss3/index.html (accessed July 16, 2005), with "Religion, Politics, and Rhetoric_-Discussed Online,” American Communication Journal 4, no. 1 (2000), http://acjournal.org/holdings/vol4/iss1/index.htm (accessed July 16, 2005).

7. Robert H. Gass and John S. Seiter, Persuasion, Social Influence, and Compliance Gaining, Pearson Education, Boston (2003).

8. See, for example, “Special Issue: Inter/Active Performance,” American Communication Journal 6, no. 3 (2003), http://acjournal.org/holdings/vol6/iss3/index.html (accessed July 16, 2005).

9. Web site tracking is a tricky business, with many sites touting "millions of hits." However, a "hit" is defined as any time data are requested from a site, including requests from another computer (such as a search engine). So in the course of one "visit" to a site, you may end up "hitting" the site hundreds of times. It is more accurate in the case of online journals to track visits, where everything a person does from the time they enter the site to the time they leave is counted as one visit, since this is more comparable to tracking how often a print journal is taken off the shelf.

10. Two clear signs that it was a student visiting the site were a) the .edu at the end of the accessing computer's IP address, combined with b) their use of unsophisticated search terms such as "communication" in the full-text search engine (which tends to turn up one or two hits on a communication journal site).

11. No such site exists as far as I know, but can't you just picture it?. 
12. Mitchell, "Both Sides Now.".

13. More information about SPARC is available on their Web site, http://www.arl.org/sparc/ (accessed July 16, 2005).

14. More information about the DOAJ is available on their Web site, http://www.doaj.org (accessed July 16, 2005).

15. More information about ASCUS is available on their Web site, http://www.ascus.info/index.html (accessed July 16, 2005).

16. Mitchell, "Both Sides Now.”.

17. Robert Schrag, “Concepts and Calls,” 2003, http://acjournal.org/edit/submit.htm (accessed July 16, 2005). 